\title{
O USO DE MATERIAIS DE DESENHO LIDOS EM ANUÁRIOS DE ENSINO DE SÃO PAULO (1907-1920)
}

\author{
Marcos Denilson Guimarães \\ Universidade Federal do Maranhão \\ markito_mat@hotmail.com
}

\begin{abstract}
RESUMO
O texto buscou identificar que tipos de materiais de ensino são recomendados e como são usados em tarefas escolares associadas ao ensino do Desenho nos cursos primário e normal de São Paulo. Para alcançar tal objetivo foram tomados para análise os Anuários de Ensino de São Paulo (19071920). Os referenciais teóricos são textos produzidos por historiadores da Educação referentes ao método de ensino intuitivo. Como resultados, percebeu-se que o papel, o lápis, os lápis de cores e o quadro negro eram os principais suportes responsáveis pela passagem da percepção/imaginação para a concretização/realização da ideia, isto é, do desenho. Em geral, a tarefa associada era favorecer o esboço pessoal e criativo do aluno por meio do desenvolvimento de suas faculdades de observação e imaginação.
\end{abstract}

Palavras-chave: Desenho. Anuário de Ensino. Materiais didáticos.

\section{THE USE OF DRAWING MATERIALS FOUND IN ANUÁRIOS DE ENSINO DE SÃO PAULO (1907-1920)}

\begin{abstract}
In this paper the aim was to identify what kind of teaching materials are recommended and how they are used in school activites associated with the teaching Drawing in the primary and normal courses of São Paulo. For this, the "Anuários de Ensino de São Paulo" (1907-1920) were examined. The theoretical references came from to texts produced by historians of Education referring to the method of intuitive teaching. As a result, it was possible to verify that paper, pencil, colored pencils and blackboard were the main supports responsible for tacklig to the passage of perception / imagination to the concretization / realization of the idea, that is, of drawing. Overall, the associated task was to favor the student's personal and creative sketch through the development of his faculties of observation and imagination.
\end{abstract}

Keywords: Drawing. Anuário de Ensino. Teaching materials.

\section{EL USO DE MATERIALES DE DIBUJO LEÍDOS EN ANUARIOS DE ENSEÑNANA DE SÃO PAULO (1907-1920)}

\section{RESUMEN}

El texto buscó identificar que tipos de materiales de enseñanza son recomendados y como son utilizados en tareas escolares asociadas al aprendizaje del Dibujo en los cursos de enseñanza 
primaria y escuela normal de São Paulo. Para alcanzar este objetivo fueron utilizados para análisis los Anuarios de Enseñanza de São Paulo (1907-1920). Los referenciales teóricos son textos producidos por historiadores de la Educación referentes al método de enseñanza intuitiva. Como resultados, se percibió que el papel, el lápiz, los lápices de colores y la pizarra eran los principales soportes responsables por el pasaje de la percepción/imaginación para la concretización/realización de la idea, es decir, del dibujo. En general, la tarea asociada era favorecer el esbozo personal y creativo del alumno por medio del desarrollo de sus facultades de observación e imaginación.

Palavras clave: Dibujo. Anuario de Enseñanza. Materiales didacticos.

\section{L'UTILISATION DE MATERIAUX DE DESSIN LUS DANS LES ANNUAIRES D'ENSEIGNEMENT DE SÃO PAULO (1907-1920)}

\section{RÉSUMÉ}

Le texte cherchait à identifier les types de matériel pédagogique recommandés et leur utilisation dans les tâches scolaires associées à l'enseignement du Dessin dans les cours primaires et normale de São Paulo. Pour atteindre cet objectif, j'analysé les Annuaires d'enseignement de São Paulo (1907-1920). Les références théoriques sont des textes produits par des historiens de l'éducation sur la méthode de l'enseignement intuitif. En conséquence, on s'est rendu compte que le papier, les crayons, les crayons de couleur et le tableau étaient les principaux supports responsables du passage de la perception/imagination à la réalisation/concrétisation de l'idée, c'est-à-dire, du dessin. En général, la tâche associée était de favoriser le dessin personnel et créatif de l'étudiant à travers le développement de ses facultés d'observation et d'imagination.

Mots-clés: Dessin. Annuaire d'enseignement. Matériaux didactiques.

\section{INTRODUÇÃO}

Considerado o ícone da escola moderna no final do século XIX, o método intuitivo, também chamado de lições de coisas e ensino pelos aspectos, tornou-se uma importante matriz discursiva de internacionalização da educação nesse período (SOUZA, 2013). Sendo, aos poucos, introduzido nas diferentes modalidades de ensino, a exemplo da escola primária, era tido pelos seus defensores como um poderoso instrumento pedagógico, capaz de modernizar o ensino e, principalmente, formar estudantes mais qualificados às transformações políticas e econômicas em curso naquela época (VALDEMARIN, 2004).

Na opinião de Souza (2000), esse fenômeno de âmbito mundial, de circulação de ideias e modelos, dos mais variados possíveis, desembocou na reflexão sobre os métodos e na ampliação dos programas de ensino, na classificação dos alunos, na distribuição dos conteúdos e no emprego do tempo, no mobiliário, nos materiais escolares, na arquitetura, na formação de professores etc. 
No caso específico da temática tratada neste artigo, Souza (2013) afirma que os materiais didáticos começaram a ser vistos como símbolos de civilização por constituírem instrumentos indispensáveis para auxiliar na passagem das percepções às ideias.

Ainda na visão da mesma autora "a ampliação da composição material das escolas primárias resultou não apenas dos novos métodos pedagógicos, mas também da diversificação e abrangência dos programas de ensino" (SOUZA, 2013, p. 107). Ou seja, com a implantação de programas mais extensos o ensino das matérias pelo método intuitivo demandava uma grande quantidade de materiais. No entanto, por medidas econômicas, a partir da década de 1920 os governos paulistas foram aos poucos restringindo a dotação material para as escolas, limitando-se à manutenção do mobiliário indispensável, tais como livros, cartilhas e alguns poucos objetos de ensino. Neste sentido, consagrou-se nas escolas o uso sistemático das cartilhas e livros de leitura e as lições rotineiras empregando o quadro negro e giz, cadernos e lápis (SOUZA, 2013).

Com as novas concepções educacionais que atentavam para a adaptação da escola ao meio social, preparando as novas gerações para viverem em uma civilização em mudança, os objetos passaram a servir de mediadores da experiência e da atividade. Citando os estudos de Valdemarin (2004), Rosa Fátima esclarece que na pedagogia da Escola Nova o objeto não era mais considerado o ponto de partida das atividades, mas sim o problema que partia da experiência do aluno. Segundo ela,

No método intuitivo, a seleção dos objetos, mesmo guardando relações com a infância, resultava de uma escolha do adulto. Na Escola Nova, os objetos de ensino são recursos auxiliares que devem ser disponibilizados pela escola para favorecer a atividade do aluno. Portanto, na pedagogia nova, os objetos de ensino perdem a centralidade adquirida na renovação pelas lições de coisas. Eles deixam de ser condição para a aquisição do conhecimento e se convertem em meios, componentes de um ambiente deliberadamente organizado para fomentar experiências de aprendizagem (SOUZA, 2013, p. 108).

Por suportes materiais de ensino, entenda-se como "os objetos utilizados por professores e aluno nas escolas em situações de ensino e aprendizagem” (SOUZA, 2013, p. 105). Essa é, portanto, a definição que norteará esta investigação. 


\section{UMA BREVE REVISÃO BIBLIOGRÁFICA SOBRE A TEMÁTICA E A QUESTÃo DE PESQUISA}

De um ponto de vista mais geral, observam-se, em trabalhos já produzidos, pistas de como os suportes materiais de ensino foram explorados na matéria de Desenho no curso primário de São Paulo.

Um primeiro trabalho desta natureza é a pesquisa feita por Leme da Silva (2014). Neste trabalho a autora tratou de discutir o uso da régua e do compasso nas matérias de Geometria e de Desenho dos programas de ensino dos estados de São Paulo, Minas Gerais, Sergipe, Goiás e Rio Grande do Sul durante o período da chamada Primeira República (1889-1930). Em se tratando do programa de São Paulo de 1894 aponta que na parte relativa ao ensino do Desenho não há, nas orientações normativas, indicações de como deveriam ser realizadas as construções de triângulos, quadrados etc. As construções em Desenho neste programa eram feitas à mão livre, isto é, sem o uso de instrumentos. A mesma coisa encontrada na análise que fez dos escritos Primeiras Lições de Desenho de Benedito Tolosa (1895). No entanto, ao consultar a obra de Olavo Freire denominada Primeiras noções de geometria prática, uma obra destinada ao ensino de Geometria, a pesquisadora afirma haver uma ruptura na relação de proximidade entre Desenho e Geometria. Ela constatou a presença de instrumentos no traçado geométrico, diferenciando-se significativamente de práticas anteriores.

No caso de Minas Gerais, a matéria apresentada é Geometria e Desenho. Dentre os programas analisados, Leme da Silva (2014) destaca o de 1906, o de 1912 idêntico ao primeiro, o de 1916 e o de 1925. Neles, os instrumentos utilizados são régua, compasso, esquadro e duplodecímetro. Para a pesquisadora, as propostas de construção de figuras geométricas e as cópias de desenhos de objetos comuns, ao natural “conviviam bem”. A inserção da Geometria e do Desenho nesses programas ocorria por meio de

instrumentos de construção, como régua e compasso, num primeiro momento destinado aos anos finais do ensino primário. Somente em 1925 a proposta ganhou uma gradação ao longo dos quatro anos e manteve os instrumentos de construção a partir do segundo ano (LEME DA SILVA, 2014, p. 88).

Resguardadas as devidas nomenclaturas, na análise às fontes do estado de Sergipe a autora constatou que "diferentemente dos Estados de São Paulo e Minas Gerais não há menção, nas 
normas e orientações do programa, de construções geométricas com instrumentos" (LEME DA SILVA, 2014, p. 89). Depara-se também com uma relação de livros adotados para o ano de 1917 em que consta a presença de Lições de coisas de Ruy Barbosa (para o professor). Para ela, tudo indica ser o manual Primeiras lições de coisas de Calkins, "considerado um marco na tentativa de implantar o método das lições de coisas no ensino brasileiro" (LEME DA SILVA, 2014, p. 89). Ademais, afirma que "o programa sergipano parece conjugar esses dois enfoques [traçado de figuras geométricas e desenho ao natural], mesmo priorizando o desenho ao natural" (LEME DA SILVA, 2014, p. 90).

Sobre o estado de Goiás, a pesquisadora identificou que inicialmente a matéria que envolvia os saberes geométricos era o Desenho Linear. Presente no programa de 1893, incorporava as práticas de construções geométricas com régua, compasso, esquadro e transferidor. Além disso, como não foi possível encontrar o programa de 1918, no programa de 1925 Geometria e Desenho é a rubrica presente nos quatro anos de ensino dos grupos escolares do referido estado. E novamente aqui há a recomendação de construção com régua e compasso. O último programa examinado foi o de 1930 que se configura como cópia do programa de São Paulo de 1925. Nele, o Desenho separase da Geometria e toma como método o desenho do natural, aquele no qual as crianças desenhavam objetos reais ao invés de linhas retas.

Já no último estado pesquisado, o Rio Grande do Sul, foram examinados dois programas: o de 1899 e o de 1910 . No primeiro,

o ensino de Desenho precede ao de Geometria e se inicia com traçado de linhas retas, à mão livre. A partir da $2^{\mathrm{a}}$ classe, sem entrar em detalhes, o Desenho acompanha as lições de Geometria, ou seja, é suporte e ferramenta para o estudo de Geometria. No estágio final, sem se desligar das lições de Geometria, incorpora o uso de régua e compasso (LEME DA SILVA, 2014, p. 93).

No entanto, é no segundo programa aonde há um detalhamento ainda maior das figuras geométricas a serem traçadas em Desenho, num primeiro momento à mão livre e, ao final do ensino, com o uso de instrumentos. De acordo com a autora, havia entre Desenho e Geometria uma "cumplicidade harmônica": os traçados eram feitos com instrumentos e o desenho de objetos naturais à mão livre, "sem necessidade de o Desenho romper com a Geometria e as construções geométricas com régua e compasso" (LEME DA SILVA, 2014, p. 93). 
Um outro trabalho que vai na mesma linha de discussão deste citado é o que foi produzido por Frizzarini (2014). O referido estudo buscou investigar as transformações que ocorreram nos programas de ensino do curso primário paulista no período de 1890 a 1950 com relação aos saberes geométricos. Nele, a autora reserva um pequeno subtópico para discutir as construções com instrumentos. Neste momento destaca que essas construções transitam em distintas matérias e se utilizam de quatro instrumentos: régua, esquadro, transferidor e compasso. No caso específico do Desenho, afirma que a determinação para o uso de instrumentos, não aponta quais, ocorre apenas nos anos de 1925 e 1949/1950.

No trabalho de dissertação elaborado por Santos (2016) a autora se propôs a compreender que materiais de ensino foram prescritos e quais seus possíveis usos no ensino dos saberes elementares matemáticos presentes nas matérias Aritmética e Desenho, no curso primário dos grupos escolares sergipanos. Privilegiou como fontes a documentação oficial do Estado durante o período de 1911 a 1931 . No tocante à temática aqui evidenciada, notou que os materiais prescritos para o ensino do Desenho gravitavam em torno de esquadros, de réguas e dos Cadernos da Coleção Olavo Freire. Como Guia do Professor para o ensino do Desenho Geométrico é citado o manual Desenho Linear de Abílio Cézar Borges. Tal manual - material de apoio ao professor, servia para a continuidade do ensino dos saberes geométricos nos anos seguintes.

Sobre a régua e o esquadro a autora afirma que nos documentos analisados não há indícios de normas ou orientações de como esses materiais devessem ser utilizados. A mesma conclusão a que chegou Leme da Silva (2014). O que conseguiu apurar foi a sua utilidade para o estudo das linhas e ângulos no programa de 1912, conforme está evidenciado na citação a seguir. "Enquanto as réguas eram prescritas aos exercícios e traçados na pedra, os esquadros serviam como material de apoio ao estudo dos ângulos que, aliado à régua, permitiam aos alunos compreenderem os diferentes tipos de ângulos: reto, agudo e obtuso" (SANTOS, 2016, p. 92). Essas recomendações estavam ligadas à prática do traçado, noutras palavras, à uma execução gráfica. No caso de São Paulo, os suportes materiais de ensino utilizados pelos alunos eram a régua, o compasso, o esquadro e o transferidor. Esses instrumentos auxiliavam o traçado de figuras geométricas na matéria de Geometria, ficando à margem o uso desses instrumentos para o ensino do Desenho.

Em suma, algo em comum nesses trabalhos analisados é o exame praticamente às mesmas fontes de pesquisas - programas de ensino. Além disso, apesar da constatação de outros instrumentos, tais como o esquadro, o transferidor e o duplo-decímetro, pode-se ver a indicação 
quase que unânime da régua e do compasso para a construção de figuras geométricas. Observa-se também a preferência pelo exame de instrumentos de ensino voltados à aprendizagem dos alunos, sem contar a ausência de uma análise mais precisa em relação ao saber Desenho.

Assim, esta revisão bibliográfica permitiu pensar que outras possibilidades de pesquisa poderiam ser adotadas neste artigo. Dessa maneira, na tentativa de identificar que tipos de materiais são recomendados e como são usados em tarefas escolares associadas ao Desenho é que foram tomados para análise os Anuários de Ensino do Estado de São Paulo entre os anos de 1907 e 1921. A escolha dessas fontes se justifica pelo fato de os Anuários - documentos produzidos pela Diretoria Geral da Instrução Pública, subordinada à Secretaria dos Negócios e do Interior, e também pela Diretoria de Ensino, ligada à Secretaria da Educação e Saúde Pública - conterem o registro de atividades escolares provenientes dos relatórios anuais expedidos pelas Delegacias Regionais de Ensino da Capital e do interior do Estado. Tais atividades dizem respeito ao movimento dos alunos, do corpo docente, das unidades escolares, das despesas, das estatísticas, da metodologia e dos processos didáticos das escolas primárias, normais, isoladas, complementares, noturnas, ginásios etc. Ademais, em relação aos professores, a publicação de um material como este servia para que os docentes "pudessem encontrar, a par de uma boa estatística e do movimento escolar de todo o Estado, uma colaboração abundante e variada sobre a parte técnica do ensino, dos métodos empregados e seus resultados práticos" (ANUÁRIO, 1907-1908, p. 17), revelando assim assuntos de interesse pedagógico e popular. Portanto, trata-se de uma investigação que busca dar conta de especificar os materiais de ensino utilizados pelos alunos e pelos professores em situações de ensino e de aprendizagem.

\section{UMA ANÁLISE DOS ANUÁRIOS DE ENSINO: ENTRE MÉTODO, MATERIAIS DE ENSINO E PRESCRIÇÕES METODOLÓGICAS PARA O ENSINO DO DESENHO}

No primeiro relatório apresentado e elaborado pelo então Inspetor Geral de Ensino, João Lourenço Rodrigues, os alunos, da $2^{\mathrm{a}}$ seção (terceiro grupo) correspondente à Escola Modelo, aos Grupos Escolares e Escolas Complementares, deveriam, durante as exposições escolares, traçar desenhos de objetos simples, animais, plantas, ditado e original. Em específico, ao observar e examinar os trabalhos de alunos do Jardim de Infância e alunos da Escola Normal elaborados para a exposição da Escola Normal e Escolas anexas de São Paulo, o referido inspetor de ensino resolveu constituir uma comissão composta por Cimbelino de Freitas, Flávia Grassi Bonilha, Felicia 
Puiggari Solá e Elisa de Macedo para estudar a organização, bem como, apresentar relatório a respeito do que foi observado. Afirma que, no caso dos trabalhos de desenho, o método adotado consistia exclusivamente na cópia de objetos naturais e de seres vivos. Os alunos eram levados a imitar formas dos corpos que tinham diante dos olhos. Nada de exercícios que adestrassem a mão, os quais, segundo o relatório, costumavam sempre enfadar os discentes.

Conforme está posto no documento, os modelos naturais, quase os mesmos para todas as escolas, eram sempre folhas, flores, objetos usuais, trabalhos em gesso, vasilhas de barro vidrado etc. Esses modelos eram esboçados ora a lápis, a crayon, pastel, bico de pena, aquarela e até carvão, “que, a nosso vêr [referindo-se ao carvão], devia ser o preferido, porque é facil, muito rapido, apaga-se sem borracha no caso de erro, e pode-se fixar muito bem depois de prompto" (ANUÁRIO, 1907-1908, p. 59).

A exposição destes trabalhos escolares servia como preparação para a seção pedagógica com que o Estado de São Paulo iria apresentar durante a Exposição Nacional no Rio de Janeiro. No plano geral enviado aos diretores de Grupos Escolares e Escolas Complementares do Estado ficou decidido que o segundo grupo, o de Material escolar, teria as seguintes recomendações:

$1^{\text {a }}$ Secção. - Moveis para o alumno: carteiras singulares e duplas, quadro negro, escovas, ponteiros, armarios.

$2^{\text {a }}$ Secção. - Utensilios: lousas, lapis, esponjas, canetas.

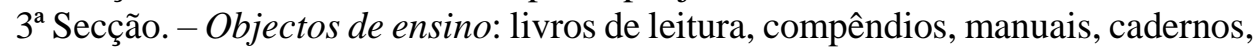
mappas, contadores mecânicos, taboleiros de areia, quadros de Parker (ANUÁRIO, 1907-1908, p. 51).

Apesar desta lista vir acompanhada de alguns suportes materiais de ensino, não há prescrições acerca do uso. Tampouco uma especificação de objetos para o ensino do Desenho. Porém, há claramente a recomendação de objetos que serviam para o ensino de saberes aritméticos, tais como os contadores mecânicos e os quadros de Parker.

Ainda neste mesmo relatório há um parecer elaborado por uma comissão e apresentado ao Secretário do Interior, Dr. Gustavo de Oliveira Godoy, acerca da adoção de livros didáticos para o curso preliminar. Os trabalhos levados a exame foram discriminados em dois grupos: a) livros didáticos e b) mapas, cadernos e materiais de ensino. No primeiro grupo estavam compreendidas duas seções: livros de leitura para o ensino da linguagem e facultativo para uso dos alunos; e compêndios e manuais que poderiam servir de guia aos professores no ensino das diversas disciplinas do programa. Relativamente ao segundo grupo, aparece uma informação importante: 
a comissão deliberou pôr á margem os cadernos de desenho, que, destoando de todo o criterio pedagógico, representariam um entrave á pratica do methodo vencedor, unico efficaz e verdadeiramente intuitivo para o ensino daquella disciplina (ANUÁRIO, 1907-1908, p. 388, grifos meus).

Pelo que foi possível apurar, estes cadernos representavam um empecilho à prática do método vencedor, ou seja, do método do Desenho ao natural, tido como eficaz e verdadeiramente intuitivo pelos reformadores. Baseando-se em Jorge Moreau, apologista e entusiasta do sistema Tadd $^{1}$, conteúdos abstratos e maçantes como os traçados retilíneos, as circunferências, os sólidos geométricos não deveriam ser mais apresentados inicialmente às crianças. Ao invés disso, a ideia era colocá-las em contato como o mundo exterior, com seu ambiente familiar, com a vida, de modo a proceder não do abstrato para o concreto, mas sim, das coisas dos seres simples, inertes ou animados, levando a criança a descobrir e traçar em seguida, com alegria, entusiasmo, as linhas vivas e flexíveis que elas exprimiam (ANUÁRIO, 1907-1908). Essas ideias, diz a comissão, justificavam "cabalmente o haver supprimido da lista de cadernos escolares os que offereciam modelos para o ensino de desenho" (ANUÁRIO, 1907-1908, p. 389). Esta medida acabou sendo posta em prática nas escolas modelo anexas à Escola Normal. Tal importância vai ao encontro daquilo que estava sendo disseminado tanto pelo programa de ensino de São Paulo de 1905 quanto nas publicações de artigos de revistas pedagógicas da época. A principal crítica à existência destes cadernos estava alicerçada na oferta de modelos prontos para o ensino do Desenho, cuja execução desses suprimia a capacidade imaginativa da criança e prejudicava o desenvolvimento de suas faculdades de observação, item tão caro para o método de ensino intuitivo. A natureza deveria ser, portanto, a principal e única fonte de inspiração das crianças.

Essa postura frente ao ensino do Desenho coadunava com as ideias defendidas por Oscar Thompson ${ }^{2}$. Segundo ele,

\footnotetext{
${ }^{1}$ Segundo Henriques (2016) (apud FIGUEIRA, 2004), o sistema Tadd era uma das vertentes do sistema americano de ensino. Liberty Tadd (1854-1917) foi diretor da escola de arte industrial de Filadélfia que, num contexto de aperfeiçoamento estético, promoveu o conceito de educação estética associado ao desenvolvimento psicomotor, por meio de uma variedade de trabalhos artísticos que integrava o desenho, a modelação e a escultura em madeira.

${ }^{2}$ Oscar Thompson formou-se pela Faculdade de Direito de São Paulo, em 1889. Foi diretor da Escola Normal da Praça (1901-1920) e diretor Interino da Escola-Modelo, anexa à Escola Normal. Viajou para os Estados Unidos em 1904. Integrou, juntamente com Sampaio Dória, o Conselho Deliberativo da Liga Nacionalista de São Paulo, entidade fundada em 1917. No âmbito dessa entidade, fez parte da Comissão de Instrução Popular.
}

Rev. Iberoam. Patrim. Histórico-Educativo, Campinas (SP), v. 5, p. .1-17, e019033, 2019. 
Ler, escrever e contar, sómente, não traduz o espirito da escola moderna. Sem duvida a leitura, a escripta e as contas são disciplinas instrumentaes, servem para se adquirirem outros conhecimentos; mas o que a escola se propõe a crear, a desenvolver principalmente é o espirito de iniciativa, de perseverança, de energia, de bondade e de dignidade. É formar homens fortes, bons e dignos, cheios de confiança em si mesmos e conscientes de sua responsabilidade. Em summa, a boa escola é aquella que se torna para a sociedade um viveiro de homens de bom caracter. Os livros de leitura, as licções oraes dos mestres, os exercicios escriptos, o desenho, os quadros que ornamentam a sala de aula devem buscar de preferencia seus motivos nos factos e scenas da vida agricola brasileira (ANUÁRIO, 19091910, p. 2).

Ainda neste mesmo relatório foi possível identificar que além de haver uma discussão a respeito dos métodos dos franceses Ravaisson e Guillaume ${ }^{3}$, o método do desenho ao natural passou a ser considerado como o único capaz de "responder ás necessidades, accommodar-se ás predilecções naturaes da criança, é o que, em summa, tiver por base a psychologia infantil”" (ANUÁRIO, 1909-1910, p. 174), onde os modelos deveriam ser objetos reais, naturais e conhecidos das crianças. O mais importante era desenvolver no indivíduo a criatividade, o raciocínio, a independência do pensamento e a sua própria personalidade. Buscava, baseado na psicologia da criança, privilegiar as suas aptidões, o seu gosto, as suas preferências pessoais. Uma outra finalidade desse ensino era servir como referência para ilustrar as lições de aula. Essa mesma tendência aparece no relatório de 1913, desta vez na tradução de contos interessantes em forma de desenho pelos alunos.

A respeito das observações das matérias do programa em vigor presentes no Anuário de 1910-1911, no caso do Desenho é ressaltado que as dificuldades com que ainda lutam muitos professores no ensino da cópia do natural se devem a falta de uma seriação gradativa, metódica, de objetos diversos. Seriação esta que deveria se basear no clássico e sábio princípio de marchar do simples para o composto. Como disse o inspetor José Carneiro da Silva,

[...], para educar, é mistér partir do facil para o difficil, do concreto para o abstracto, tendo em vista desenvolver no alumno o espirito de iniciativa, espontaneidade na pesquisa da verdade. Para tal fim, isto é, para que o ensino interesse vivamente o alumno, é indispensavel que elle tenha sempre um alcance pratico. Na escola moderna todo o ensino se resume n'uma acção que o alumno possa praticar (ANUÁRIO, 1910-1911, p. 58).

\footnotetext{
${ }^{3}$ Para mais informações sobre estes dois franceses, consultar Rates (2019).

Rev. Iberoam. Patrim. Histórico-Educativo, Campinas (SP), v. 5, p. .1-17, e019033, 2019.
} 
Relativo ao desenho, é muito comum o aluno procurar desenhar, não a parte ou partes do objeto por ele vista, mas todo o objeto como ele o imagina. Caberia, portanto, ao professor corrigir tal defeito, "observando, na ocasião da aula, os trabalhos de seus alumnos, dirigi-los, um por um, mostrando-lhes as condições em que deve ser desenhado o modelo, attentas as condições de posição, de distancia, etc.” (ANUÁRIO, 1910-1911, p. 43). Ademais, ressalta que o uso de modelos grandes é mais vantajoso em virtude do destaque nítido dos detalhes.

Para facilitar a uniformidade de orientação do ensino, umas das insatisfações apresentadas em relatórios anteriores pelos inspetores de ensino, ficava estabelecido que no ensino do Desenho a pretensão principal seria educar a vista e adestrar ambas mãos por meio da cópia de objetos naturais e não de modelos. Para isso, um dos materiais de ensino utilizados era o quadro negro conforme está descrito a seguir. "O professor guia, indica e por fim em largos traços no quadro negro, dá idéa do desenho, mas deverá limpar immediatamente o quadro negro, afim de que os alumnos não vão copiar os trabalhos naturalmente imperfeitos, pela rapidez com que são executados" (ANUÁRIO, 1911-1912, p. 24).

No ano seguinte, mais uma vez o inspetor de ensino Ramon Roca Dordal dá o seu parecer sobre o ensino do Desenho. Desta vez, entre as páginas CIV-CXV, Dordal manifesta inicialmente certa preocupação com o número de aulas e com o exíguo tempo dedicado ao ensino desta matéria escolar. Para ele seria indispensável consignar no horário três aulas por semana para cada classe, sendo de 20 minutos nas classes do $1^{\circ}$ ano, de $25 \mathrm{~min}$. nas do $2^{\circ}$ ano e de $30 \mathrm{~min}$. nas de $3^{\circ}$ e $4^{\circ}$ anos. Considerando que o estudo do desenho devesse partir da observação do objeto a ser desenhado, "até a criança que ainda não sabe escrever já procura, pelo desenho, traduzir as suas impressões. O desenho é para ella uma nova fórma de linguagem escripta” (ANUÁRIO, 1913, p. $\mathrm{CV}$ ). Mais adiante, o autor aponta que "nada mais natural do que tornar collectivas no desenho as lições que, de principio, deverão ser dadas no quadro negro" (ANUÁRIO, 1913, p. CV). Nota-se mais uma vez a recorrência feita ao quadro como suporte do ensino.

Ainda neste artigo o autor faz uma severa crítica ao ensino de desenho de figuras geométricas. Conforme ele, esse método de ensino obrigava as crianças a fazerem cópias de desenhos de figuras geométricas que para elas são inteiramente inexpressivas,

que lhes desagradava, que não lhes despertava o menor interesse, ao envez de, observando a sua inclinação, orientá-las, afim de que, reproduzindo de memória ou copiando objetos que lhes agradasse, fossem ellas próprias o melhor fator de

Rev. Iberoam. Patrim. Histórico-Educativo, Campinas (SP), v. 5, p. .1-17, e019033, 2019. 
educação de suas faculdades de observação, de memória, de testemunho, de comparação (ANUÁRIO, 1913, p. CVI).

Para criar entusiasmo diante desse enfadonho método, muitos professores fazem a distribuição de lápis de cores. Neste sentido, "manifesta-se alegria geral, que attinge até o professor, ao verificar que os trabalhos são mais completos, melhor executados e, sobretudo, porque, a não haver casos de anomalia visual, a maioria emprega as côres com certo criterio e, muita vez, com certo gosto" (ANUÁRIO, 1913, p. CVI). Tem-se aí duas predileções: desenhar de memória e empregar cores que mais lhes agradam e tornam o desenho elaborado mais vivo, mais colorido. Ademais, "Os primeiros exercícios de desenho serão feitos no quadro negro, com giz de differentes côres, limitando-se á reproducção de bolas, fructos, objectos feitos pelas crianças na aula de modelagem" (ANUÁRIO, 1913, p. CVI). Percebe-se, portanto, pela primeira vez uma ênfase notória ao uso do lápis ou giz de cor como um dos objetos utilizados pelos alunos para o ensino do Desenho. Isso porque o desenho colorido "presta-se á educação da vista, pela observação das côres e proporcionalidade dos objectos, presta-se a noções de grandezas, fraccionarias, como $\frac{\mathbf{1}}{\mathbf{2}}, \frac{\mathbf{1}}{\mathbf{3}}, \frac{\mathbf{1}}{\mathbf{4}}$ etc, adestra as mãos e, sobretudo, desenvolve a energia e a vontade" (ANUÁRIO, 1913, p. CIX). Essa mesma recomendação do uso de lápis de diversas cores é timidamente apontado no programa paulista de 1905.

$\mathrm{Na}$ aula seguinte, supondo-se que a maioria desenhou bolas ou frutas na aula anterior, recomenda-se ao professor que apresente a classe algumas laranjas e um ou dois balões de borracha. Toda a classe observaria as frutas, pegando, mostrando e comparando as cores e superfícies, estabelecendo posteriormente uma palestra entre professor e alunos acerca do balão e da laranja. A escolha do que desenhar ficaria com a classe. Em seguida, "Vai a criançada ao quadro negro, cujos bordos têm muitos bastões de giz de differentes côres; cada um escolhe a côr mais proxima do balão. Dahi a pouco, até onde as crianças alcançam, está o quadro repleto de balões vermelhos" (ANUÁRIO, 1913, p. CVII). A crítica do próprio trabalho fica a cargo do aluno. O professor apenas fará observações de modo que o aluno encontre e corrija o seu próprio defeito. "Os alumnos, que fizeram os melhores trabalhos, irão reproduzil-os noutra aula, no papel, com lapis de côr" (ANUÁRIO, 1913, p. CVII). A reprodução no papel facilita a compreensão de tamanho e proporcionalidade. Assim, neste exercício "a criança [...] agiu com memória motora, visual, auditiva, teve impressões tácteis, impressões vivas", isso porque "as coisas que interessam as crianças, permanecem mais tempo gravadas em sua memória, e deixam impressões associadas ás 
condições do meio em que as coisas ou objectos estiveram e foram observados" (ANUÁRIO, 1913, p. CVII). O autor aponta que a observação que recomenda está pautada na propaganda feita pelas escolas suíças, a partir de um trabalho realizado pelas professoras Mina Andernars e Louise Lafendel.

“Cultivando o desenho de memória de par com a reproducção do natural, permittindo ilustrar os trabalhos gráficos, já, estou certo, muito se terá conseguido" (ANUÁRIO, 1913, p. CX). Para completar a série de estudos de formas, o passo seguinte é o estudo do quadrado, feito a partir da reprodução de retângulos cuja base seja o dobro da altura e posterior divisão ao meio. "A distribuição de grande numero de regoinhas ou taboinhas estreitas, de fitas de papel de côr, dará applicações em trabalhos manuais e todos elles serão depois desenhados" (ANUÁRIO, 1913, p. CXI). Outra maneira de aproveitamento do desenho é por meio da descrição de passeios, ao jardim público. A observação deste lugar possibilitava aos alunos moldarem de memória ou sob modelo, barquinhos de papel e os cisnes do lago. O auxílio a revistas velhas é também outro meio de completar o ensino do desenho para os casos de desenhos mal feitos. "Os quadros transformáveis no quadro negro, acompanhando a evolução de uma história, são de extraordinaria influencia na linguagem oral. Despertam a attenção e levam os alumnos a observações minuciosas" (ANUÁRIO, 1913, p. CXI).

A defesa do autor é a mesma dos inspetores anteriores: o ensino do desenho do natural. Por isso, "Convém, pois é racional, que o professor vá ao encontro dessa tendencia natural, encaminhando-as, conduzindo-a, imprimindo-lhe ordem garantidora de sucesso" (ANUÁRIO, 1913, p. CXIII). É por meio do desenho do natural que cai por terra toda a pretensão de fazer do menino que frequenta a escola primária um artista no desenho, exigindo dele belos quadros, trabalhos perfeitos. O professor se contentará com apenas aquilo que a criança por si só consegue realizar e que juntamente associado à geografia, à história, às ciências físicas e naturais, auxiliado pela tecelagem, dobradura, modelagem, "tem real influencia educativa sobre a observação, a memoria, o testemunho, a comparação, o raciocínio, unico capaz de preparar a criança á verdadeira compreensão do bello" (ANUÁRIO, 1913 p. CXIII). Vale mencionar também o emprego de diferentes suportes materiais de ensino como as réguas ou tábuas estreitas de fitas de papel de cor e as revistas velhas.

Após 6 anos sem registro de informações sobre o Desenho lidas nos Anuários precedentes, consta no relatório de 1920 que a respeito do programa das escolas primárias de São Paulo o ensino 
do Desenho deveria ser sobre os assuntos retirados da vida local, que expressassem fatos cotidianos como a sucessão das estações, sobre a vida agrícola ou industrial etc. A natureza exercia o seu papel principal de fonte de inspiração e informação para os traçados do desenho. Sobre ela, as crianças eram indagadas sobre o que viam, o que sabiam sobre a existência de qualquer coisa e como as imaginavam. Naquela época, dizia Sampaio Dória que “[...] formar o cidadão não era dotálo de um conhecimento enciclopédico [...], mas formá-lo desenvolvendo sua capacidade de conhecer, sentir, querer e agir como tal" (CARVALHO, 2010, p. 101). A ênfase pedagógica nos conteúdos de ensino era descolada para outras práticas de atividades. A ligação com a vida prática de todos os dias era algo mais importante. Os desenhos deveriam ser feitos sem o auxílio de modelos. Vale mencionar ainda que eram efetuados desenhos que lembrassem os sólidos geométricos já estudados anteriormente. Neste caso, desenhariam figuras como casas, igrejas ou monumentos que recordassem tais formas. Continuavam, no segundo ano, os exercícios do primeiro. A publicação neste Anuário, relativa ao ensino de Desenho, é idêntica a do programa de São Paulo de 1921. Desta maneira, pode-se pensar que o programa paulista tenha se apropriado das ideias apresentadas neste Anuário.

\section{CONSIDERAÇÕES FINAIS}

O século XX rompeu definitivamente com a ideia de que ensinar desenho era equivalente a construir figuras geométricas à mão livre. Com a ampliação deste discurso e a difusão do método do desenho ao natural em países estrangeiros e sua total adoção pelos franceses em 1909, pôde-se verificar que este discurso foi também apropriado pelas escolas primárias e normais brasileiras. Cronologicamente falando, todos os Anuários de Ensino do estado de São Paulo analisados mostram que a recomendação era a de que se adotasse o método baseado na cópia de desenhos e objetos reais que despertasse a imaginação e a criatividade das crianças. Além de constituir um modo de adestrar as mãos e olhos, possibilitava-lhes uma aguçada capacidade inventiva e de observação. Indicou-se que os conteúdos fossem estruturados com base naquilo que a natureza ofertava. Noutras palavras, o método tendia a relacionar a vida social da criança com a vida escolar dela. Um excelente meio de privilegiar as suas aptidões, os seus gostos e suas preferências para aquilo que mais lhe agradava. Uma matéria que extraía da natureza os motivos para conduzir as tarefas escolares. 
Tomando como hipótese teórica a afirmação de Souza (2013) de que no método intuitivo os materiais didáticos começaram a ser vistos como símbolos de civilização por constituírem instrumentos indispensáveis para auxiliar na passagem das percepções às ideias, buscou-se investigar especificamente para o caso do Desenho a existência ou não destes materiais e a quais tipos de tarefas eles estavam associados. Percebeu-se então que em relação aos materiais de ensino o papel, o quadro negro, o lápis e os lápis de cores eram os principais suportes responsáveis pela passagem da percepção/imaginação para a concretização/realização da ideia, isto é, do desenho. Os modelos naturais utilizados eram quase sempre os mesmos: folhas, flores, frutos, objetos de uso social etc. A marcha se dava do simples para o complexo. Baseando-se na psicologia infantil, o simples em Desenho consistia na execução de desenhos espontâneos, ou seja, desenhos elaborados sem a pretensão de rigor geométrico, favorecendo assim o esboço pessoal e criativo do aluno. Ao traduzir suas impressões no papel em forma de desenhos as crianças exerciam o princípio da observação, algo tão requerido no método intuitivo. A reprodução no papel facilitava a compreensão do tamanho e da proporcionalidade.

No caso do quadro negro, tanto nas escolas primárias quanto normais, este servia para que fosse dada uma ideia geral do desenho, limpando-o imediatamente a fim de que os alunos não fizessem a cópia dele, mas que utilizassem da observação para concluir o desenho solicitado. Já os lápis de cores, bem enfatizado no Anuário de 1913, estavam associados à tarefa de prestar-se à educação da vista e das mãos, às noções de grandezas fracionárias etc.

Para finalizar, cabe destacar que associado ao desenho ao natural estavam prescritos outros tipos de desenhos, tais como de memória, de ilustração, de ornamentação, de livre iniciativa e colorido. Esses desenhos assumiam papeis importantes para o estabelecimento de consensos sobre o desenho do natural que de forma objetivada se tornam imprescindíveis para a formação do aluno e do professor. Espaços como programas de ensino e Anuários de ensino constituem-se, portanto, meios que viabilizam essa circulação de ideias e práticas escolares.

\section{REFERÊNCIAS}

ANUÁRIO DE ENSINO DO ESTADO DE SÃO PAULO. Publicação organizada pela Inspetoria Geral do Ensino por ordem do Governo do Estado. São Paulo: Typ. Augusto Siqueira \& C., 1907-1908. Disponível em: < 
http://200.144.6.120/uploads/acervo/periodicos/anuarios_ensino/AEE19070000.pdf >. Acesso em: 01 mar. 2019.

. Publicação organizada pela Inspetoria Geral do Ensino por ordem do governo do Estado. São Paulo: Typ. Siqueira, Salles \& C., 1908-1909. Disponível em: < http://200.144.6.120/uploads/acervo/periodicos/anuarios_ensino/AEE19080000.pdf>. Acesso em: 01 mar. 2019.

. Publicação Organizada pela Diretoria Geral da Instrução Pública por ordem do governo do Estado. São Paulo: Typographia do Diário Official, 1909-1910. Disponível em: < http://200.144.6.120/uploads/acervo/periodicos/anuarios_ensino/AEE19090000.pdf>. Acesso em: 01 mar. 2019.

. Publicação Organizado pela diretoria geral da Instrução Pública por ordem do governo do Estado. São Paulo: Typ. Siqueira, Nagel \& C., 1910-1911. Disponível em: < http://200.144.6.120/uploads/acervo/periodicos/anuarios_ensino/AEE19100000.pdf >. Acesso em: 01 mar. 2019.

. Publicação Organizado pela diretoria geral da Instrução Pública por ordem do governo do Estado. São Paulo: Typ. Siqueira, Nagel \& C., 1911-1912. Disponível em:< http://200.144.6.120/uploads/acervo/periodicos/anuarios_ensino/AEE19110000.pdf $>$. Acesso em: 01 mar. 2019.

. Publicação Organizado pela diretoria geral da Instrução Pública por ordem do governo do Estado. São Paulo: Typ. Siqueira, 1913. Disponível em:< http://200.144.6.120/uploads/acervo/periodicos/anuarios_ensino/AEE19130000.pdf>. Acesso em: 01 mar. 2019.

. Publicação Organizado pela diretoria geral da Instrução Pública por ordem do governo do Estado. São Paulo, 1920-1921. Disponível em: < http://200.144.6.120/uploads/acervo/periodicos/anuarios_ensino/AEE19200000.pdf>. Acesso em: 01 mar. 2019.

CARVALHO, M. M. C. Sampaio Dória. Coleção Educadores MEC. Recife: Fundação Joaquim Nabuco, Editora Massangana, 2010.

FRIZZARINI, C. R. B. Do ensino intuitivo para a escola ativa: os saberes geométricos nos programas do curso primário paulista. 2014. 160f. Dissertação (Mestrado em Educação e Saúde) - Universidade Federal de São Paulo, Guarulhos.

HENRIQUE, D. M. B. Ser educado, ser educador: a dimensão filosófica, ética e pedagógica da obra de Luiza Andaluz. 2016. 371f. Tese (Faculdade de Psicologia e de Ciências da Educação) Universidade de Coimbra, Portugal. 
LEME DA SILVA, C. M. Régua e compasso no ensino primário? Circulação e apropriação de práticas normativas para as matérias de Desenho e Geometria. História da Educação [Online]. Porto Alegre, n. 44, v. 18, set./dez. 2014, pp. 79-97.

RATES, B. B. Natureza e cultura na filosofia de Bergson. 2019. 402f. Tese (Programa de PósGraduação em Filosofia) - Universidade Federal de São Carlos, São Paulo.

SANTOS, J. C. Materiais de ensino e os saberes elementares matemáticos, Sergipe (19111931). 2016. 120f. Dissertação (Mestrado em Ensino de Ciências e Matemática/NPGECIMA/UFS) - Universidade Federal de Sergipe, São Cristóvão.

SOUZA, R. F. Inovação educacional no século XIX: a construção do currículo da escola primária no Brasil. In: Cadernos Cedes (UNICAMP), Campinas, v. 51, pp. 33-44, 2000.

Objetos de ensino: a renovação pedagógica e material da escola primária no Brasil, no século XX. In: Educar em Revista, Editora UFPR, Curitiba, n. 49, jul./set., 2013, pp. 103-120.

VALDEMARIN, V. T. Estudando as lições de coisas. $1^{\text {a }}$. ed. Campinas: Autores Associados, 2004.

Recebido em: 21 de maio de 2019 Aceito em: 18 de dezembro de 2019 